\title{
PURWARUPA BIKELIFT VERTICAL SCREW KAPASITAS BEBAN 200 KG
}

\author{
Ahmad Kholil, Wardoyo, Aly Muharram \\ Prodi Pendidikan Teknik Mesin Fakultas Teknik Universitas Negeri Jakarta \\ Email : ahmadkholil@unj.ac.id
}

\begin{abstract}
ABSTRAK
Bikelift merupakan alat bantu angkat sepeda motor. Bikelift biasanya berpenggerak hidrolik atau pneumatik dan biasanya dipakai di bengkel-bengkel yang tidak mudah untuk mobilisasi. Penelitian ini bertujuan untuk membuat purwarupa bikelift sistem ulir vertikal dengan kapasitas beban maksimal sepeda motor $200 \mathrm{~kg}$. Bikelift dikembangkan bersifat mampu jinjing. Untuk itu perlu diketahui waktu yang dibutuhkan untuk mengangkat sepeda motor sampai ketinggian $80 \mathrm{~cm}$ pada proses pendongkrakan manual dan pendongkrakan menggunakan impact.

Metode perancangan yang digunakan adalah dengan menentukan kriteria perancangan, identifikasi dan survei lapangan, perancangan dan perhitungan, pengujian dan analisa. Dari perancangan ini didapatkan dimensi poros berulir yang digunakan adalah diameter inti 15,5 mm, diameter nominal $20 \mathrm{~mm}$, jarak antar puncak ulir $4 \mathrm{~mm}$, dan area inti $189 \mathrm{~mm}$, serta daya angkat yang dibutuhkan adalah 162,64 watt. Pada proses pendongkrakan manual waktu yang dibutuhkan untuk mengangkat beban sepeda motor $90 \mathrm{~kg}$ adalah 278 detik, beban $110 \mathrm{~kg}$ adalah 317 detik, beban $150 \mathrm{~kg}$ adalah 431 detik, dan pada beban $200 \mathrm{~kg}$ adalah 619 detik. Pada proses pendongkrakan menggunakan impact waktu yang dibutuhkan untuk mengangkat beban sepeda motor $90 \mathrm{~kg}$ adalah 57 detik, beban $110 \mathrm{~kg}$ adalah 67 detik, beban $150 \mathrm{~kg}$ adalah 107 detik, dan pada beban $200 \mathrm{~kg}$ adalah 159 detik.
\end{abstract}

Kata kunci: purwarupa, bikelift, ulir vertikal

\section{Latar Belakang}

Bikelift adalah alat yang digunakan untuk mengangkat sepeda motor. Bikelift yang ada di Indonesia umumnya digerakkan dengan sistem hidrolik, sistem pneumatik, maupun sistem ulir, yang sebagian besar berbentuk meja, ukurannya besar dan berat, serta harganya cukup mahal. Oleh karena itu, muncullah pemikiran untuk membuat bikelift yang ringan dan mudah untuk dipindahpindah serta harganya yang lebih murah. Dari ketiga sistem pengangkatan pada bikelift tersebut dipilihlah bikelift dengan sistem ulir, karena sistem ulir biaya pembuatannya lebih murah daripada sistem hidrolik dan sistem pneumatik.

Pada umumnya bikelift dengan sistem ulir, poros berulir yang digunakan sebagai penerus daya diletakkan dalam posisi horisontal. Karena posisi horisontal memakan banyak tempat, maka muncul ide bikelift dengan sistem ulir vertikal yaitu ke atas supaya tidak memakan banyak tempat. Selain itu, bikelift yang akan dibuat komponennya bisa dirakit dan dapat dipindah-pindah dengan mudah, serta bisa dioperasikan dengan cara manual yaitu menggunakan tuas dengan tenaga manusia dan bisa dioperasikan pula dengan tenaga motor listrik seperti impact electric.

\section{Tujuan Penelitian}

Tujuan yang ingin dicapai dari penelitian ini yaitu :

1. Mengetahui dimensi poros berulir yang akan digunakan dalam bikelift sistem ulir vertikal dengan kapasitas beban maksimal sepeda motor seberat $200 \mathrm{~kg}$.

2. Mengetahui daya angkat yang dibutuhkan bikelift sistem ulir vertikal dengan kapasitas beban maksimal sepeda motor seberat $200 \mathrm{~kg}$.

3. Mengetahui waktu yang dibutuhkan untuk mengangkat sepeda motor sampai ketinggian $80 \mathrm{~cm}$ pada proses pendongkrakan manual.

4. Mengetahui waktu yang dibutuhkan untuk mengangkat sepeda motor sampai ketinggian $80 \mathrm{~cm}$ pada proses pendongkrakan dengan menggunakan impact. 


\section{Kajian Teori}

\subsection{Poros}

Sebuah poros adalah elemen mesin berputar yang digunakan untuk memindahkan daya dari satu tempat ke tempat lain. Daya ini dikirim ke poros oleh beberapa gaya tangensial dan torsi yang dihasilkan ( atau memutar saat ) dibentuk dalam poros memungkinkan daya untuk ditransfer ke berbagai mesin dihubungkan ke poros. Bahan yang digunakan untuk poros biasa adalah baja karbon dari nilai $40 \mathrm{C} 8,45$ C 8, 50 C 4 dan 50 C 12 .

\subsection{Ulir Daya}

Ulir daya adalah alat yang dipakai dalam permesinan untuk mengubah gerakan rotasi menjadi gerakan linier, dan biasanya memindahkan daya. Pemakaiannya yang umum termasuk antara lain ulir penuntun pada mesin bubut dan ulir untuk ragum, alat penekan, dan dongkrak. Menghitung daya angkat pada ulir daya :

$$
\begin{aligned}
& N=\frac{\text { Kecepatan putaran }}{\text { Jarak antar puncak ulir }} \\
& \omega=\frac{2 \pi N}{60} \\
& \mathrm{P}=T . \omega
\end{aligned}
$$

\subsection{Perancangan Dongkrak Ulir}

Sebuah dongkrak ulir botol untuk mengangkat beban ditunjukkan pada Gambar 1.

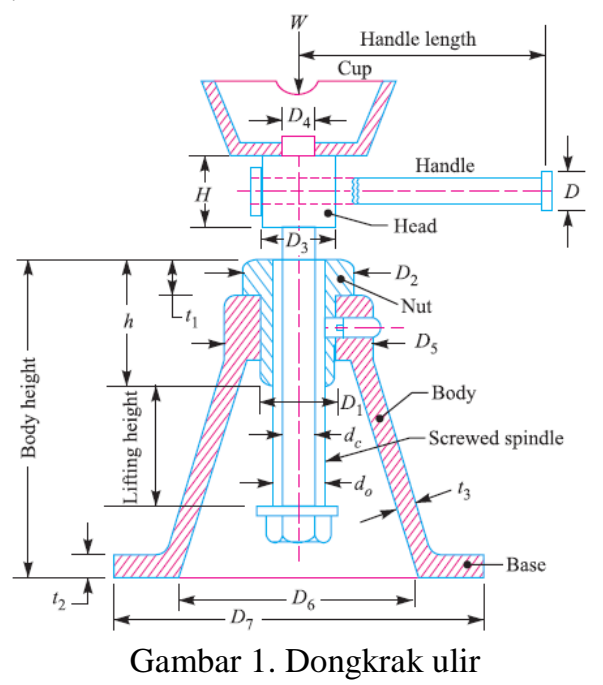

Untuk merancang sebuah dongkrak ulir untuk beban $\mathrm{W}$, dilakukan prosedur sebagai berikut : a. Pertama-tama, menemukan diameter inti ( $d_{c}$ ) dengan mempertimbangkan bahwa sekrup di bawah tekanan murni, yaitu :

$$
W=\sigma_{c} \cdot A_{c}=\sigma_{c} \cdot \frac{\pi}{4}\left(d_{c}\right)^{2}
$$

b. Cari torsi ( $T$ ) yang diperlukan untuk memutar sekrup dan menemukan tegangan geser $(\tau)$ karena torsi ini. Kita tahu bahwa torsi yang dibutuhkan untuk mengangkat beban,

$$
T=P \cdot \frac{d}{2}=W \tan (\alpha+\phi) \frac{d}{2}
$$

di mana:

$\mathrm{P}=$ usaha yang dibutuhkan untuk memutar sekrup

$\mathrm{d}=$ diameter rata-rata dari sekrup

$\therefore$ tegangan geser akibat torsi,

$$
\tau=\frac{16 T}{\pi\left(d_{c}\right)^{3}}
$$

menemukan tegangan tekan langsung ( $\sigma_{c}$ ) akibat beban aksial,

$$
\sigma_{c}=\frac{W}{\frac{\pi}{4}\left(d_{c}\right)^{2}}
$$

c. Cari tekanan yang digunakan sebagai berikut :

Maksimum tegangan utama ( tarik atau tekan ),

$$
\sigma_{c(\max )}=\frac{1}{2}\left[\sigma_{c}+\sqrt{\sigma_{c}^{2}+4 \tau^{2}}\right]
$$

dan tegangan geser maksimum,

$$
\tau_{\max }=\frac{1}{2} \sqrt{\left(\sigma_{c}\right)^{2}+4 \tau^{2}}
$$

Tekanan tersebut harus kurang dari tekanan yang diijinkan.

d. Cari ketinggian mur ( $h$ ), mengingat tekanan bantalan pada mur. Kita tahu bahwa bantalan tekanan pada mur,

di mana :

$$
p_{b}=\frac{W}{\frac{\pi}{4}\left[\left(d_{o}\right)^{2}-\left(d_{c}\right)^{2}\right] n}
$$

$\mathrm{n}=$ jumlah ulir yang berhubungan dengan sekrup

$\therefore$ Tinggi mur, $\quad \mathrm{h}=\mathrm{n} \times \mathrm{p}$

di mana :

$\mathrm{p}=$ jarak antar puncak ulir

e. Periksa ketegangan pada sekrup dan mur sebagai berikut :

$$
\begin{aligned}
\tau_{(\text {screw })} & =\frac{W}{\pi \cdot n \cdot d_{c} \cdot t} \\
\tau_{(\text {nut })} & =\frac{W}{\pi \cdot n \cdot d_{o} \cdot t}
\end{aligned}
$$


di mana :

$\mathrm{t}=$ ketebalan sekrup $=p / 2$

f. Cari diameter mur $(D)$. Diameter $(D)$ ditemukan dengan mempertimbangkan kekuatan robeknya mur. Kita tahu bahwa,

$$
W=\frac{\pi}{4}\left[(D)^{2}-\left(d_{o}\right)^{2}\right] \sigma_{t}
$$

g. Dengan asumsi bahwa kekuatan rata-rata manusia sebesar $5 \mathrm{~kg}=49,03325 \mathrm{~N}$, maka panjang pegangan yang dibutuhkan, $=T / 49,03325$

Panjang pegangan dapat diperpanjang untuk mempermudah memutar ulir.

h. Diameter pegangan $(D)$ dapat diperoleh dengan mempertimbangkan efek lentur. Kita tahu bahwa momen lentur, $\left(\because \sigma_{b}=\sigma_{t}\right.$ or $\left.\sigma_{c}\right)$

$$
M=\frac{\pi}{32} \times \sigma_{b} \times D^{3}
$$

i. Ketinggian kepala ( $H$ ) biasanya diambil sebagai dua kali diameter pegangan, yaitu

$$
H=2 D
$$

j. Sekarang periksa beban kritis yang dapat membuat sekrup melengkung. Panjang efektif atau panjang yang tidak didukung sekrup untuk dapat melengkung,

$$
L=\text { Tinggi angkat }+\frac{1}{2} \text { Tinggi mur }
$$

Kita tahu bahwa tekuk atau beban kritis,

$$
W_{c r}=A_{c} \times \sigma_{y}\left[1-\frac{\sigma_{y}}{4 C \pi^{2} E}\left(\frac{L}{k}\right)^{2}\right]
$$

di mana :

$\sigma_{y}=$ Kekuatan luluh

$C=$ Akhir koefisien ketetapan. Sekrup dianggap menekan ujung bawah tetap dan ujung beban bebas. Untuk satu ujung tetap dan ujung lainnya bebas, $C=0,25$ $k=$ Radius rotasi $=0,25 d_{\mathrm{c}}$

Beban kritis seperti yang diperoleh dari rumus di atas harus lebih tinggi dari beban di mana sekrup dirancang.

k. Cari efisiensi dongkrak ulir.

$$
\eta=\frac{T 0}{T}
$$

\section{Metode Perancangan}

Untuk mempermudah langkah-langkah perancangan yang lebih teratur, maka dibuat diagram alir perancangan seperti di bawah ini

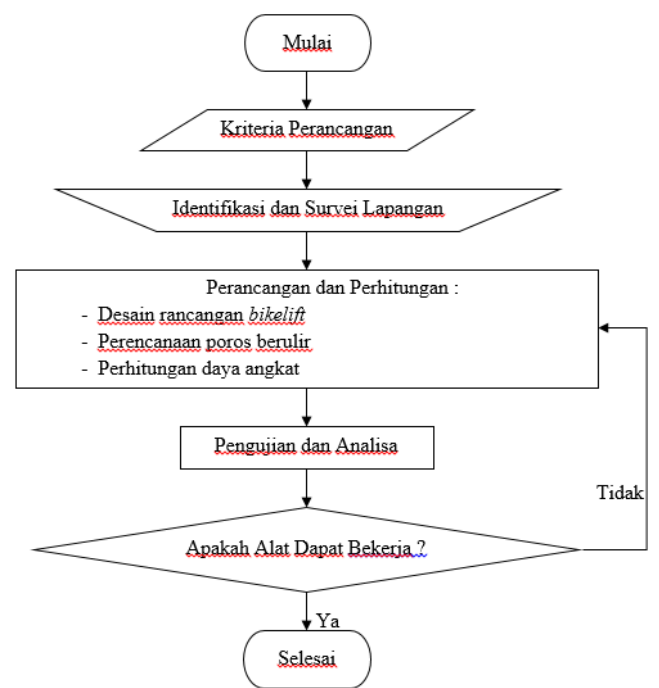

Gambar 2. Diagram alir perancangan

Bikelift ini memiliki kriteria seperti :

a. Kapasitas beban $200 \mathrm{~kg}$.

b. Beban diangkat sampai ketinggian $80 \mathrm{~cm}$.

c. Bahan poros berulir beserta murnya yang digunakan adalah S45C8.

d. Harga komponen yang digunakan murah dan terjangkau.

e. Komponen standar yang digunakan mudah didapat.

f. Komponen yang dirancang mudah dibuat.

g. Mudah dalam pemeliharan dan perawatannya.

\section{Hasil Dan Pembahasan}

\subsection{Hasil Perhitungan}

- Desain sekrup.

Dari hasil perhitungan didapat diameter inti dari sekrup $=7,018 \mathrm{~mm}$, maka untuk amannya dipilih poros berulir dengan dimensi :

Diameter inti $\left(d_{c}\right)=15,5 \mathrm{~mm}$

Diameter nominal $\left(d_{o}\right)=20 \mathrm{~mm}$

Jarak antar puncak ulir $(p)=4 \mathrm{~mm}$

Area inti $\left(A_{c}\right)=189 \mathrm{~mm}^{2}$.

- Desain mur.

Dari hasil perhitungan didapat diameter mur $=21,19 \mathrm{~mm}$, katakanlah 22 $\mathrm{mm}$.

- Desain tuas.

Dari hasil perhitungan didapat 90,56 $\mathrm{mm}$ untuk panjang pegangan, $11,38 \mathrm{~mm}$ untuk diameter pegangan, dan $24 \mathrm{~mm}$ untuk ketinggian kepala pegangan, untuk mempermudah memutar ulir maka 
panjang pegangan yang digunakan adalah $150 \mathrm{~mm}$ dan $12 \mathrm{~mm}$ untuk diameter pegangan.

- $\quad$ Efisiensi sekrup $25 \%$.

- $\quad$ Daya angkat $=162,64$ watt

- Usaha untuk memutar ulir pada beban 90 $\mathrm{kg}$ adalah 22,96 kg, beban $110 \mathrm{~kg}$ adalah $28,06 \mathrm{~kg}$, beban $150 \mathrm{~kg}$ adalah $38,26 \mathrm{~kg}$, dan pada beban $200 \mathrm{~kg}$ adalah $51,02 \mathrm{~kg}$.

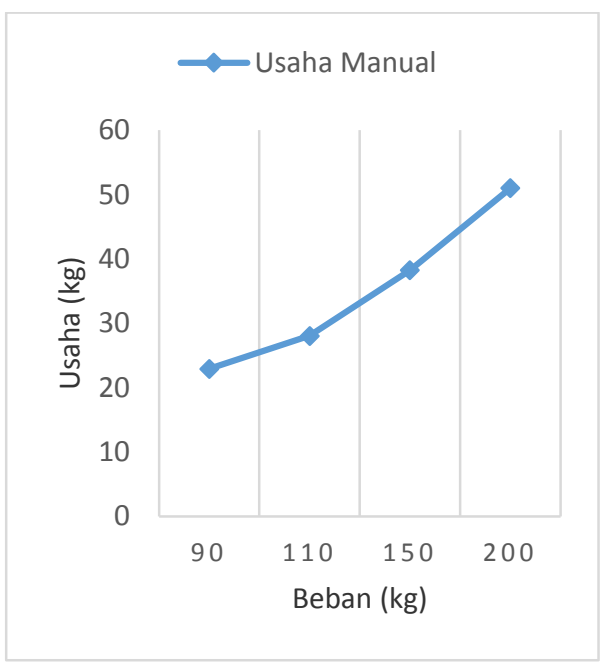

Gambar 3. Usaha untuk memutar ulir

Dari gambar 3 dapat diketahui bahwa semakin berat beban yang didongkrak, maka semakin besar pula usaha yang dikeluarkan. Usaha untuk memutar ulir pada beban $90 \mathrm{~kg}$ adalah 22,96 kg, beban $110 \mathrm{~kg}$ adalah 28,06 $\mathrm{kg}$, beban $150 \mathrm{~kg}$ adalah $38,26 \mathrm{~kg}$, dan pada beban $200 \mathrm{~kg}$ adalah $51,02 \mathrm{~kg}$.

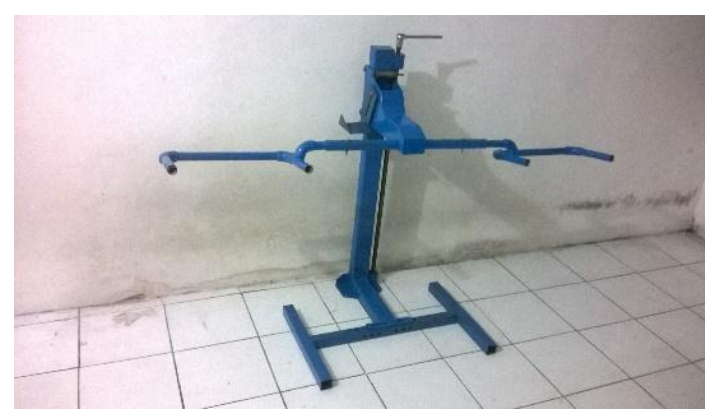

Gambar 4. Bikelift anpa beban

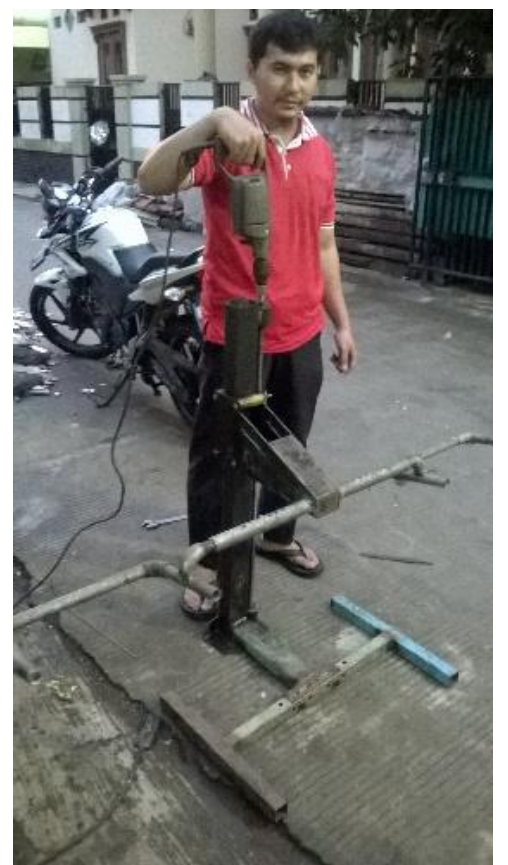

Gambar 5. Pengujian pendongkrakan dengan impact tanpa beban

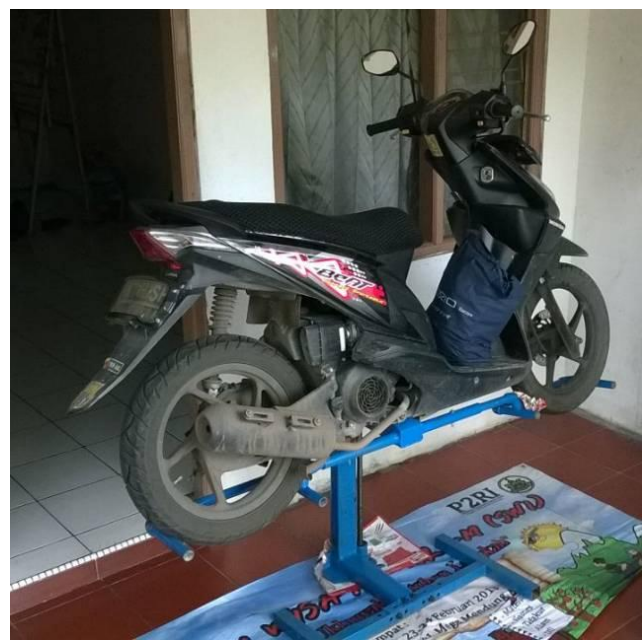

Gambar 6. Pendongkrakan dengan beban sepeda motor $(90 \mathrm{~kg})$. 


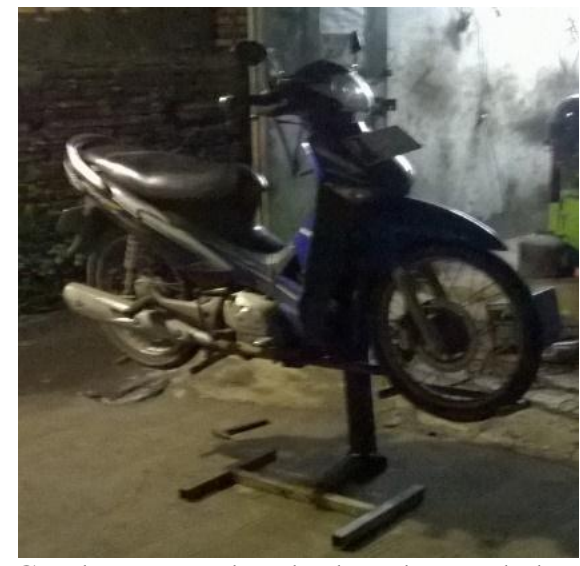

Gambar 7. Pendongkrakan dengan beban sepeda motor $(110 \mathrm{~kg})$

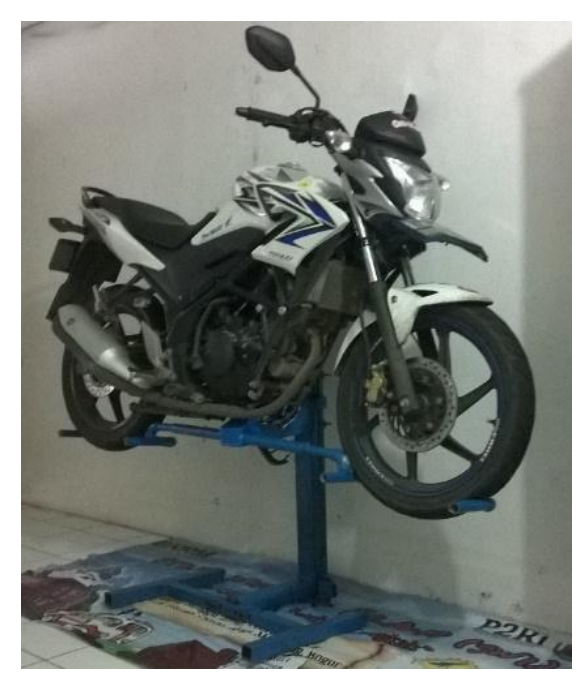

Gambar 8. Pendongkrakan dengan beban sepeda motor $(150 \mathrm{~kg})$

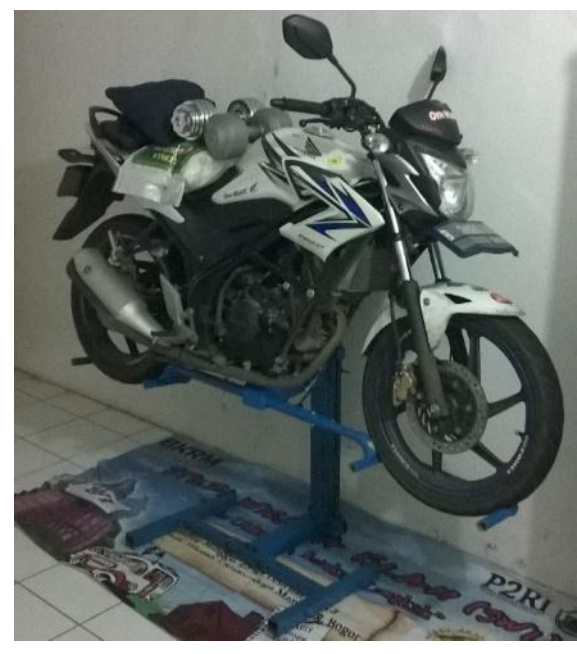

Gambar 9. Pendongkrakan dengan beban sepeda motor $(200 \mathrm{~kg})$.

\subsection{Hasil Pengujian}

Pengujian pendongkrakan manual dengan beban sepeda motor ( $90 \mathrm{~kg}$ ), sepeda motor ( $110 \mathrm{~kg}$ ), sepeda motor ( $150 \mathrm{~kg}$ ), dan sepeda motor ( $200 \mathrm{~kg}$ ) sampai dengan ketinggian 80 $\mathrm{cm}$ dilihat pada tabel berikut.

Tabel 1. Hasil pengujian dengan manual

\begin{tabular}{|c|c|c|c|}
\hline No & $\begin{array}{l}\text { Berat } \\
\text { Sepeda } \\
\text { Motor }\end{array}$ & $\begin{array}{l}\text { Waktu } \\
\text { (detik) }\end{array}$ & $\begin{array}{c}\text { Rata-rata } \\
\text { (detik) }\end{array}$ \\
\hline \multirow{3}{*}{1} & \multirow{3}{*}{$90 \mathrm{~kg}$} & 281 & \multirow{3}{*}{278} \\
\hline & & 276 & \\
\hline & & 278 & \\
\hline \multirow{3}{*}{2} & \multirow{3}{*}{$110 \mathrm{~kg}$} & 319 & \multirow{3}{*}{317} \\
\hline & & 318 & \\
\hline & & 314 & \\
\hline \multirow{3}{*}{3} & \multirow{3}{*}{$150 \mathrm{~kg}$} & 435 & \multirow{3}{*}{431} \\
\hline & & 429 & \\
\hline & & 432 & \\
\hline \multirow{3}{*}{4} & \multirow{3}{*}{$200 \mathrm{~kg}$} & 622 & \multirow{3}{*}{619} \\
\hline & & 620 & \\
\hline & & 616 & \\
\hline
\end{tabular}

Pengujian pendongkrakan menggunakan alat impact dengan beban sepeda motor ( $90 \mathrm{~kg})$, sepeda motor $(110 \mathrm{~kg}$ ), sepeda motor ( $150 \mathrm{~kg}$ ), dan sepeda motor ( $200 \mathrm{~kg}$ ) sampai dengan ketinggian $80 \mathrm{~cm}$ dilihat pada tabel berikut.

Tabel 2. Hasil pengujian dengan alat impact

\begin{tabular}{|c|c|c|c|}
\hline No & $\begin{array}{l}\text { Berat } \\
\text { Sepeda } \\
\text { Motor }\end{array}$ & $\begin{array}{l}\text { Waktu } \\
\text { (detik) }\end{array}$ & $\begin{array}{c}\text { Rata-rata } \\
\text { (detik) }\end{array}$ \\
\hline \multirow{3}{*}{1} & \multirow{3}{*}{$90 \mathrm{~kg}$} & 58 & \multirow{3}{*}{57} \\
\hline & & 57 & \\
\hline & & 56 & \\
\hline \multirow{3}{*}{2} & \multirow{3}{*}{$110 \mathrm{~kg}$} & 68 & \multirow{3}{*}{67} \\
\hline & & 65 & \\
\hline & & 69 & \\
\hline \multirow{3}{*}{3} & \multirow{3}{*}{$150 \mathrm{~kg}$} & 108 & \multirow{3}{*}{107} \\
\hline & & 109 & \\
\hline & & 105 & \\
\hline \multirow{3}{*}{4} & \multirow{3}{*}{$200 \mathrm{~kg}$} & 158 & \multirow{3}{*}{159} \\
\hline & & 157 & \\
\hline & & 161 & \\
\hline
\end{tabular}

Perbandingan waktu pendongkrakan manual dengan pendongkrakan menggunakan alat impact. 


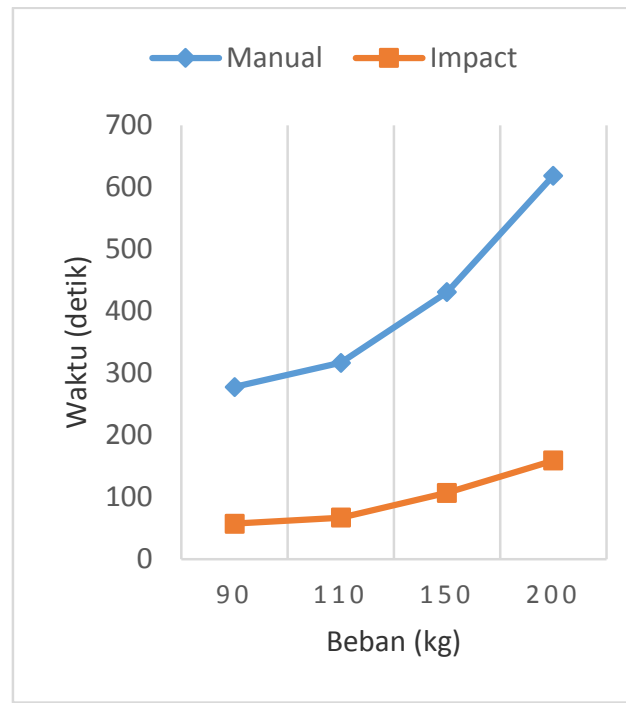

Gambar 10. Perbandingan waktu angkat manual dengan alat impact

Dari gambar 10, maka dapat diketahui bahwa waktu yang dibutuhkan untuk pendongkrakan manual dan pendongkrakan menggunakan impact sangat berbeda. Hal ini dikarenakan kecepatan putaran poros ulir yang terjadi pada proses pendongkrakan menggunakan impact berputar lebih cepat, sehingga beban yang diangkat dapat terangkat cepat. Namun berbeda dengan lama waktu pada proses pendongkrakan manual jauh lebih lama, karena kecepatan putaran manual dengan tangan tidak secepat putaran dengan menggunakan impact.

\section{Kesimpulan}

Kesimpulan dari penelitian ini, adalah :

a. Dimensi poros berulir yang digunakan adalah : diameter inti $=15,5 \mathrm{~mm}$, diameter nominal $=20 \mathrm{~mm}$, jarak antar puncak ulir $=4 \mathrm{~mm}$, area inti $=189 \mathrm{~mm}^{2}$.

b. Daya angkat yang dibutuhkan adalah 162,64 watt.

c. Pada proses pendongkrakan manual sampai ketinggian $80 \mathrm{~cm}$, waktu yang dibutuhkan untuk mengangkat sepeda motor : $90 \mathrm{~kg}$ adalah 278 detik, $110 \mathrm{~kg}$ adalah 317 detik, $150 \mathrm{~kg}$ adalah 431 detik, dan $200 \mathrm{~kg}$ adalah 619 detik.

d. Pada proses pendongkrakan dengan impact sampai ketinggian $80 \mathrm{~cm}$, waktu yang dibutuhkan untuk mengangkat sepeda motor : $90 \mathrm{~kg}$ adalah 57 detik, 110 $\mathrm{kg}$ adalah 67 detik, $150 \mathrm{~kg}$ adalah 107 detik, dan $200 \mathrm{~kg}$ adalah 159 detik.

\section{Daftar Pustaka}

[1] Budynas Richard G. and J. Keith Nysbett. 2008. Shigley's Mechanical Engineering Design, Eighth Edition. New York : McGraw-Hill Companies, Inc.

[2] Dudung, Agus. 2012. Merancang Produk. Bandung : PT Remaja Rosdakarya.

[3] Khurmi R.S. \& J.K. Gupta. 2005. A Textbook Of Machine Design (S.I. Units). New Delhi : Eurasia Publishing House (PVT.) LTD.

[4] Pulat, Mustafa B. 1992. Fundamentals of Industrial Ergonomics. New Jersey, USA : Prentice-Hall Inc.

[5] Sidney. McCormick, E.J \& Sander, M.S. 1987. Human Factor in Engineering and Design, Sixth Edition. New York : McGraw-Hill Companies, Inc.

[6] Sutalaksana. 2006. Teknik Perancangan Sistem Kerja, Edisi Kedua. Penerbit ITB, Bandung.

[7] Ulrich, K. T, \& Eppinger, Steven D. 2001. Product Design and Development. New York : McGrawHill Companies Inc. 